\title{
TERT promoter mutations in thyroid cancer
}

\section{Rengyun Liu and Mingzhao Xing}

Laboratory for Cellular and Molecular Thyroid Research, Division of Endocrinology, Diabetes and Metabolism, The Johns Hopkins University School of Medicine, 1830 East Monument Street, Suite 333, Baltimore, Maryland 21287, USA
Correspondence should be addressed to $M$ Xing Email mxing1@jhmi.edu

\begin{abstract}
The 2013 discovery of Telomerase reverse transcriptase (TERT) promoter mutations chr5, $1,295,228$ C > T (C228T) and 1,295,250 C > T (C250T) in thyroid cancer represents an important event in the thyroid cancer field and much progress has occurred since then. This article provides a comprehensive review of this exciting new thyroid cancer field. The oncogenic role of TERT promoter mutations involves their creation of consensus binding sites for E-twenty-six transcriptional factors. TERT C228T is far more common than TERT C250T and their collective prevalence is, on average, $0,11.3,17.1,43.2$ and $40.1 \%$ in benign thyroid tumors, papillary thyroid cancer (PTC), follicular thyroid cancer, poorly differentiated thyroid cancer and anaplastic thyroid cancer, respectively, displaying an association with aggressive types of thyroid cancer. TERT promoter mutations are associated with aggressive thyroid tumor characteristics, tumor recurrence and patient mortality as well as BRAF V600E mutation. Coexisting BRAF V600E and TERT promoter mutations have a robust synergistic impact on the aggressiveness of PTC, including a sharply increased tumor recurrence and patient mortality, while either mutation alone has a modest impact. Thus, TERT with promoter mutations represents a prominent new oncogene in thyroid cancer and the mutations are promising new diagnostic and prognostic genetic markers for thyroid cancer, which, in combination with BRAF V600E mutation or other genetic markers (e.g. RAS mutations), are proving to be clinically useful for the management of thyroid cancer. Future studies will specifically define such clinical utilities, elucidate the biological mechanisms and explore the potential as therapeutic targets of TERT promoter mutations in thyroid cancer.
\end{abstract}
Key Words
- TERT promoter mutation
- thyroid cancer
- telomerase reverse transcriptase
- BRAF V600E mutation
- genetic molecular markers
- prognosis
- diagnosis

\section{Introduction}

\section{Telomerase reverse transcriptase in human cancer}

Telomerase reverse transcriptase (TERT) is the catalytic protein subunit of telomerase, which, together with an integral RNA subunit and several species-specific assessor proteins, functions to add telomeres - tandem repeats of TTAGGG sequence - at the end of chromosomes (Moyzis et al. 1988), maintaining chromosomal integrity and genome stability (Greider \& Blackburn 2004, Blasco 2005).
Telomerase is well expressed in germ line and stem cells but less expressed or repressed in most somatic human cells; in the latter, telomere loss occurs during each round of cell division, causing cells to enter senescence when a critical length of telomeres is reached (Harley \& Villeponteau 1995, Blasco 2005). In contrast, telomerase is reactivated in many human cancers (Kim et al. 1994,

Published by Bioscientifica Ltd 
Shay \& Bacchetti 1997), which prevents the happening of critical telomere shortening, thus enabling cancer cells acquire replicative immortality (Hanahan \& Weinberg 2011). Compared with the RNA subunit, TERT plays a dominant role in the activation of telomerase during malignant transformation of cells (Feng et al. 1995, Meyerson et al. 1997, Bodnar et al. 1998, Hahn et al. 1999, Janknecht 2004). TERT can also modulate the expression of growth-controlling genes (Smith et al. 2003), directly regulate NFкB-dependent gene expression (Ghosh et al. 2012), and stabilize MYC levels on chromatin (Koh et al. 2015).

Given these and other functions of TERT, it has been proposed that TERT may act as an oncogene in a telomereindependent manner (Wyatt et al. 2010). In fact, overexpression of TERT, or naturally occurring alternatively spliced TERT variants that lack telomerase activities, stimulated rapid cell proliferation without changes of telomere length in human and murine cells (Smith et al. 2003, Sarin et al. 2005, Choi et al. 2008, Hrdlickova et al. 2012). Induced expression of TERT was also shown to promote the development of mammary carcinomas and epidermal tumors in vivo (Gonzalez-Suarez et al. 2001, Stewart et al. 2002). Inversely, TERT knockdown decreased cell proliferation and suppressed tumor growth in a xenograft model (Ghosh et al. 2012). Reactivation of TERT has also been linked to several other cancer hallmark behaviors, such as resistance to antigrowth signals, angiogenesis, resistance to apoptosis, invasion and metastasis, inflammation and immune surveillance, reprogramming of energy metabolism and genome instability (Low \& Tergaonkar 2013).

Genome-wide association studies have identified multiple variants at the TERT locus that are associated with telomere length and risk of several cancers (Rafnar et al. 2009, Bojesen et al. 2013, Codd et al. 2013, Wang et al. $2014 a$ ), strongly suggesting that this locus is a common susceptibility locus for human cancer. The most significant advance in understanding the genetic role of TERT in human cancer was the landmark finding of mutations in the promoter of the TERT gene in melanoma early in 2013 through whole-genome sequencing (Horn et al. 2013, Huang et al. 2013), which were quickly found also in other human cancers, such as bladder cancer and glioblastoma (Killela et al. 2013, Liu et al. 2013a) as well as thyroid cancer (Liu et al. 2013b). There are two common recurrent TERT promoter mutations in human cancer that are located at two hotspots: chr5, 1,295,228 C > T (C228T) and $1,295,250 \mathrm{C}>\mathrm{T}$ (C250T), corresponding to the positions 124 and $146 \mathrm{bp}$ respectively upstream of the
TERT translation start site. These two TERT promoter mutations occurred in a mutually exclusive manner, with C228T being far more dominant than C250T in most cancers. Both mutations generate a consensus binding site in the TERT promoter for E-twenty-six (ETS) transcription factors, which has been shown to confer the TERT promoter increased transcriptional activities (Horn et al. 2013, Huang et al. 2013, Bell et al. 2015). This provides a mechanistic explanation for the oncogenic role of TERT promoter mutations in human cancer.

\section{Thyroid cancer}

Thyroid cancer is the most common endocrine malignancy, which has seen a rapidly rising incidence in recent decades (Siegel et al. 2014, Howlader et al. 2015). Thyroid cancer is histologically classified into follicular thyroid cell-derived papillary thyroid cancer (PTC), follicular thyroid cancer (FTC), poorly differentiated thyroid cancer (PDTC) and anaplastic thyroid cancer (ATC), and parafollicular C cell-derived medullary thyroid cancer (MTC), which classically account for $\sim 80,10,5,2$ and $3 \%$ of all thyroid malignancies, respectively (Hundahl et al. 1998), with PTC emerging to be even more dominant in recent years (Howlader et al. 2015). PTC can be further classified into several histological variants, the most common of which are conventional PTC (CPTC), follicular variant PTC (FVPTC) and tall-cell PTC (TCPTC). Among follicular cell-derived thyroid cancers, PTC and FTC are differentiated thyroid cancer with a generally indolent disease course while ATC, albeit uncommon, is an undifferentiated thyroid cancer with a rapid aggressive disease course; PDTC has an intermediate aggressive course between DTC and ATC. There is also thyroid Hürthle cell cancer (HCC), which is uncommon and conventionally treated as a type of FTC. Since our first report of TERT promoter mutations in various types of thyroid cancer in 2013 (Liu et al. 2013b), there have been a large number of more studies on this topic published, reporting and characterizing TERT promoter mutations in thyroid cancer (Landa et al. 2013, Vinagre et al. 2013, Cancer Genome Atlas Research Network 2014, Liu \& Xing 2014, Liu et al. 2014a,b, Melo et al. 2014, Wang et al. 2014b,c, Xing et al. 2014a, de Biase et al. 2015, Chindris et al. 2015, Crescenzi et al. 2015, Dettmer et al. 2015, Gandolfi et al. 2015, Lee et al. 2015, Muzza et al. 2015, Qasem et al. 2015, Shi et al. 2015). This is an exciting new thyroid cancer research field, which has progressed rapidly just in this past 2 years; much has now already been known about the biological role and clinical significance of TERT promoter

Published by Bioscientifica Ltd. 
ERC 150533-1/2/2016-16:12-SANKARS-551507-XML StyleD - pp. 143-155

Review

$R$ Liu and M Xing

TERT and thyroid cancer

$23: 3$

R145

mutations in thyroid cancer. This review focuses on TERT promoter mutations in thyroid cancer and summarizes the progresses in recent research and clinical development of this young but rapidly mushrooming field. We included all the studies on TERT promoter mutations in thyroid cancer published in English in PubMed as of November 2015 with identifiable information on thyroid tumor types. The pooled analyses included nonselective cases from different studies available for the analyzed parameters as presented in the corresponding tables and figures and did not include four studies which were each focused on highly selective special cases, including pediatric thyroid cancer (Ballester et al. 2015), papillary thyroid microcarcinomas (PTMC) (de Biase et al. 2015), tall-cell PTC (Dettmer et al. 2015) and distant-metastasis PTC (Gandolfi et al. 2015).

\section{Common occurrence of TERT promoter mutations in thyroid cancer}

The most common TERT promoter mutations are C228T and C250T in human cancers. As initially demonstrated (Liu et al. 2013b), studies have generally shown no overlap between TERT C228T and C250T mutations and the former is far more prevalent than the latter in thyroid cancer. This pattern is uniformly seen regardless of the ethnic and geographical backgrounds of the studies (Table 1). Specifically, on the overall analysis, the prevalences of $\mathrm{C} 228 \mathrm{~T}$ and $\mathrm{C} 250 \mathrm{~T}$ are 9.7 and $2.1 \%$ in PTC, 15.7 and 2.5\% in FTC, 33.8 and $15.0 \%$ in PDTC, 37.7 and $4.1 \%$ in ATC respectively,. The relative distribution of TERT C228T between the two mutations is dominantly 82.5, 86.2, 69.2 and 90.2\% in PTC, FTC, PDTC and ATC respectively. The mutual exclusivity of the two TERT promoter mutations suggests that either may function sufficiently to play an important role in thyroid tumorigenesis although which one is more powerful oncogenically has not been established at this time. Unless otherwise specified, the analyses and discussions in this review will be on the two TERT promoter mutations collectively.

Our initial study reported a prevalence of TERT C228T and C250T mutations to be collectively $0 \%$ in benign thyroid tumors, $38-46 \%$ in PDTC and ATC, and $12-14 \%$ in PTC and FTC (Liu et al. 2013b). This pattern of prevalence was confirmed in many other studies as summarized in Table 2. Specifically, on the analysis of the pooled data, the two TERT promoter mutations were found collectively in 11.3, 17.1, 14.6, 43.2 and 40.1\% of PTC, FTC, HCC, PDTC and ATC respectively. No TERT promoter mutation was

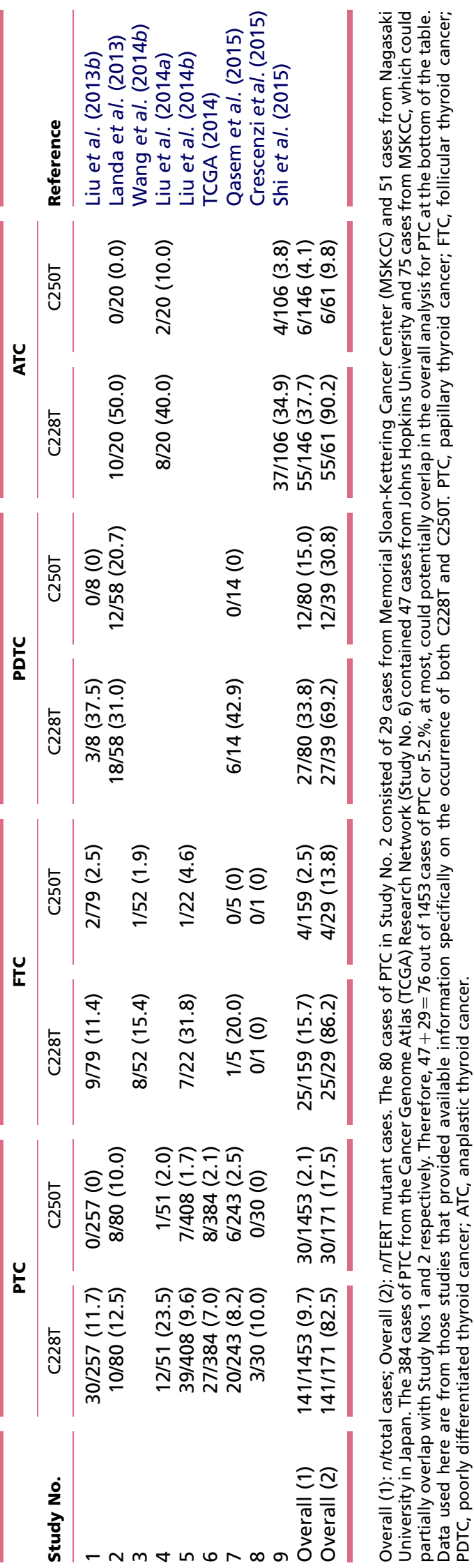

Published by Bioscientifica Ltd. 
found in MTC. Of the total of 363 benign thyroid neoplasms from various studies, only one sample was reported to harbor TERT promoter mutation (C228T). It should be noted, though, that this case of patient with TERT promoter mutation-positive benign thyroid neoplasm later developed tumor recurrence and died of FTC, raising question on the histological nature of the benign tumor (Wang et al. 2014b). Thus, the prevalence of TERT promoter mutations in the large number of true benign thyroid neoplasms is $0 \%$.

TERT promoter mutation is a rare genetic event in PTMC as demonstrated in the study of de Biase et al. (2015) which examined the TERT promoter mutation status in 431 PTMC and found a prevalence of $4.7 \%$; this prevalence is much lower than that seen on the analyses of thyroid cancers of all tumor sizes (Table 2). TERT promoter mutation appears to also be uncommon in pediatric thyroid cancers as suggested by the study of Ballester et al. (2015), which found no TERT promoter mutation in 27 pediatric thyroid cancers, including 25 PTC, 1 FTC and 1 MTC. Larger studies on pediatric thyroid cancer, however, are needed to confirm this finding. Our initial study (Liu et al. 2013b) demonstrated a prevalence distribution of TERT promoter mutations among the three main variants of PTC in the order of TCPTC $\gg$ CPTC $>$ FVPTC. Several subsequent studies have analyzed the distribution pattern of TERT promoter mutations in PTC variants and generally found the prevalence to be similarly highest in TCPTC and lowest in FVPTC. Specifically, as summarized in Table 3, the prevalence of TERT promoter mutations is $25.0 \%$ in TCPTC, $9.6 \%$ in CPTC and 8.0\% in FVPTC. Lee et al. (2015) did not found TERT promoter mutation in ten cases of hobnail-variant PTC analyzed.

The presence of TERT promoter mutations provides a genetic mechanisms for the upregulation of TERT in thyroid cancer since these mutations create binding consensus sites in the TERT promoter for ETS transcriptional factors (Horn et al. 2013, Huang et al. 2013, Bell et al. 2015), which upregulate genes, including the TERT gene. In fact, two studies directly demonstrated an association of TERT promoter mutations with increased TERT expression in thyroid cancers (Vinagre et al. 2013, Muzza et al. 2015). This seems to be consistent with the previous findings that telomerase activity and TERT expression were undetectable in normal thyroid tissues

Table 2 Frequency of TERT promoter mutations in various thyroid tumors

\begin{tabular}{|c|c|c|c|c|c|c|c|c|}
\hline \multirow[b]{2}{*}{$\begin{array}{l}\text { Study } \\
\text { No. }\end{array}$} & \multicolumn{7}{|c|}{ Frequency (mutation/total (\%)) } & \multirow[b]{2}{*}{ Reference } \\
\hline & PTC & FTC & $\mathrm{HCC}$ & PDTC & ATC & MTC & $\begin{array}{l}\text { Benign } \\
\text { neoplasm }\end{array}$ & \\
\hline 1 & $30 / 257(11.7)$ & $11 / 79(13.9)$ & & $3 / 8(37.5)$ & $25 / 54(46.3)$ & $0 / 16(0)$ & $0 / 85(0)$ & Liu et al. (2013b) \\
\hline 2 & $18 / 80(22.5)$ & & $4 / 25(16.0)$ & $30 / 58(51.7)$ & $10 / 20(50.0)$ & & & Landa et al. (2013) \\
\hline 3 & $13 / 169(7.7)$ & 9/64 (14.1) & & $3 / 14(21.4)$ & 2/16 (12.5) & $0 / 28(0)$ & $0 / 72(0)$ & Vinagre et al. (2013) \\
\hline 4 & $5 / 111(4.5)$ & $4 / 18(22.2)$ & & & & & $0 / 166(0)$ & Liu \& Xing (2014) \\
\hline 5 & & 9/52 (17.3) & & & & & $1 / 58(1.7)$ & Wang et al. (2014b) \\
\hline 6 & & & & & & $0 / 39(0)$ & & Wang et al. (2014c) \\
\hline 7 & $13 / 51(25.5)$ & $8 / 36(22.2)$ & & & $10 / 20(50 \%)$ & $0 / 37(0)$ & & Liu et al. (2014a) \\
\hline 8 & $46 / 408(11.3)$ & $8 / 22(36.4)$ & & & & & $0 / 44(0)$ & Liu et al. (2014b) \\
\hline 9 & $25 / 332(7.5)$ & $12 / 70(17.1)$ & & $9 / 31(29.0 \%)$ & $12 / 36(33.3 \%)$ & $0 / 28(0)$ & $0 / 72(0)$ & Melo et al. (2014) \\
\hline 10 & $61 / 507(12.0)$ & & & & & & & Xing et al. (2014a) \\
\hline 11 & $36 / 384(9.4)$ & & & & & & & TCGA (2014) \\
\hline 12 & $26 / 243(10.7)$ & $1 / 5(20.0)$ & 1/3 (33.3) & 6/14 (42.9) & & & & Qasem et al. (2015) \\
\hline 13 & $3 / 30(10.0)$ & $0 / 1(0)$ & & & & & $0 / 17(0)$ & Crescenzi et al. (2015) \\
\hline 14 & & & $8 / 61(13.1)$ & & & & & Chindris et al. (2015) \\
\hline 15 & & & & & 41/106 (38.7) & & & Shi et al. (2015) \\
\hline 16 & 22/182 (12.1) & $8 / 58(13.8)$ & & & & $0 / 14(0)$ & $0 / 6(0)$ & Muzza et al. (2015) \\
\hline Overall & $250 / 2217(11.3)$ & 49/287 (17.1) & $13 / 89(14.6)$ & 48/111 (43.2) & 73/182 (40.1) & $0 / 97(0)$ & $1 / 363(0.3)$ & \\
\hline
\end{tabular}

Study Nos 1, 4 and 10 were from one group of the same investigators; Study Nos 3 and 9 were from another group of the same investigators; and Study Nos 5, 6 and 7 were from still another group of the same investigators. To avoid overlap, only the cases from the largest study from each of the three groups of investigators are included for the overall analyses at the bottom of the table. For the reason explained in the footnotes of Table 1, 76/2,217 or $3.4 \%$, at most, could potentially overlap on the overall analysis for PTC at the bottom of the table. The one case of patient with TERT promoter mutationpositive benign thyroid neoplasm later developed tumor recurrence and died of FTC, raising question on the histological nature of the benign tumor (Wang et al. 2014b). Thus, the prevalence of TERT promoter mutations in the large number of remaining true benign thyroid neoplasms is $0 \%$. PTC, papillary thyroid cancer; FTC, follicular thyroid cancer; HCC, thyroid Hürthle cell cancer; PDTC, poorly differentiated thyroid cancer; ATC, anaplastic thyroid cancer; MTC, medullary thyroid cancer. 
ERC 150533-1/2/2016-16:12-SANKARS-551507-XML StyleD - pp. 143-155

Table 3 TERT promoter mutations in three main variants of papillary thyroid cancer

\begin{tabular}{|c|c|c|c|c|}
\hline \multirow[b]{2}{*}{ Study No. } & \multicolumn{3}{|c|}{ Frequency (mutation/total (\%)) } & \multirow[b]{2}{*}{ Reference } \\
\hline & CPTC & FVPTC & TCPTC & \\
\hline 1 & 23/187 (12.3) & 2/56 (3.6) & 4/13 (30.8) & Liu et al. (2013b) \\
\hline 2 & $12 / 110(10.9)$ & $0 / 39(0)$ & & Vinagre et al. (2013) \\
\hline 3 & $19 / 230(8.3)$ & $5 / 74(6.8)$ & $0 / 2(0)$ & Melo et al. (2014) \\
\hline 4 & 47/383 (12.3) & $8 / 103(7.8)$ & $5 / 19(26.3)$ & Xing et al. (2014a) \\
\hline 5 & $25 / 270(9.3)$ & $5 / 81(6.2)$ & $6 / 29(20.7)$ & TCGA (2014) \\
\hline 6 & $10 / 153(6.5)$ & $7 / 56(12.5)$ & $9 / 30(30)$ & Qasem et al. (2015) \\
\hline 7 & $12 / 143(8.4)$ & & & Muzza et al. (2015) \\
\hline Overall & $113 / 1179(9.6)$ & 25/314 (8.0) & $20 / 80(25.0)$ & \\
\hline
\end{tabular}

Study Nos 1 and 4 were from a group of the same investigators. Study Nos 2 and 3 were from another group of the same investigators. To avoid overlap, only the cases from the largest study of each group are included in the overall analysis at the bottom of the table. For the reason explained in Tables 1 and 2 overall, 47/1,573, or 3.0\%, at most, has a potential overlap with the TCGA data. CPTC, conventional papillary thyroid cancer; TCPTC, tall-cell papillary thyroid cancer; FVPTC, follicular-variant papillary thyroid cancer.

and infrequently detectable in benign thyroid tumors, but TERT reactivation was frequently observed in thyroid cancers (Umbricht et al. 1997, Saji et al. 1999, Asaad et al. 2006). Compared with PTC and FTC, high TERT expression was more commonly observed in ATC (Ito et al. 2005), which is consistent with the distribution patterns of TERT promoter mutations among these thyroid cancers (Tables 1 and 2). Interestingly, knockdown of TERT using the antisense approach in human thyroid cancer cells inhibited telomerase activity in vitro and diminished tumor growth in vivo (Teng et al. 2003), providing the functional evidence for an oncogenic role of TERT in thyroid tumorigenesis. These data are all consistent with and support an important role of the TERT promoter mutations in thyroid tumorigenesis.

\section{Association of TERT promoter mutations with clinicopathological outcomes of thyroid cancer}

A striking feature of TERT promoter mutations in thyroid cancer is their association with poor clinicopathological outcomes of the tumor, which has been consistently observed in different studies. The relationship between TERT promoter mutations and various clinicopathological parameters of thyroid cancer is summarized in Table 4. All the studies, except one on ATC (Liu et al. $2014 a$ ), consistently demonstrated a significant association between TERT promoter mutations and older patient age. On the pooled analysis, the patient age is $59.2 \pm 15.5$ vs $44.9 \pm 15.6$ years in TERT mutation-positive vs mutation-negative patients $(P<0.001)$. Interestingly,

Table 4 Summary of association between TERT promoter mutations and clinicopathological outcomes of thyroid cancer

\begin{tabular}{|c|}
\hline Clinicopathological outcomes \\
\hline 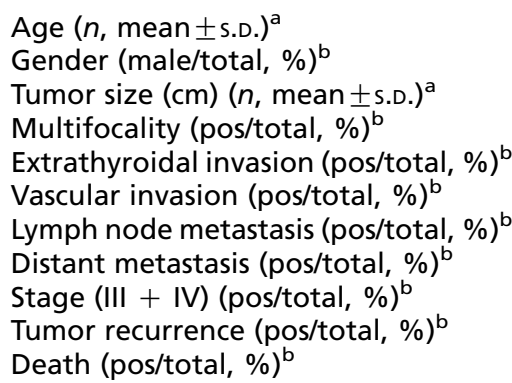 \\
\hline
\end{tabular}

\begin{tabular}{l}
\multicolumn{1}{c}{ All types } \\
\multicolumn{1}{c}{ TERT WT } \\
\hline $2110,44.9 \pm 15.6$ \\
$580 / 2335(24.8)$ \\
$1666,2.69 \pm 1.93$ \\
$364 / 872(41.7)$ \\
$516 / 1430(36.1)$ \\
$265 / 933(28.4)$ \\
$531 / 1210(43.9)$ \\
$109 / 1037(10.5)$ \\
$434 / 1687(25.7)$ \\
$179 / 956(18.7)$ \\
$23 / 413(5.6)$ \\
\hline
\end{tabular}

\begin{tabular}{l}
$\begin{array}{c}\text { s of thyroid cancer } \\
\text { TERT mutant }\end{array}$ \\
\hline $327,59.2 \pm 15.5$ \\
$132 / 353(37.4)$ \\
$263,3.93 \pm 2.68$ \\
$43 / 123(35.0)$ \\
$119 / 214(55.6)$ \\
$49 / 116(42.2)$ \\
$91 / 178(51.1)$ \\
$64 / 193(33.2)$ \\
$128 / 218(58.7)$ \\
$75 / 144(52.1)$ \\
$26 / 62(41.9)$ \\
\hline
\end{tabular}

$\begin{array}{r}\multicolumn{1}{c}{P} \\ \hline<0.001 \\ <0.001 \\ <0.001 \\ 0.152 \\ <0.001 \\ 0.002 \\ 0.070 \\ <0.001 \\ <0.001 \\ <0.001 \\ <0.001 \\ \hline\end{array}$

\begin{tabular}{|c|c|c|}
\hline \multicolumn{3}{|c|}{ Papillary thyroid cancer } \\
\hline TERT WT & TERT mutant & $P$ \\
\hline $1781,43.4 \pm 14.8$ & $212,55.7 \pm 15.7$ & $<0.001$ \\
\hline 408/1786 (22.8) & $80 / 212$ & $<0.001$ \\
\hline $1389,2.30 \pm 1.52$ & $161,2.92 \pm 1.97$ & $<0.001$ \\
\hline $332 / 770(43.1)$ & $36 / 97(37 . \overline{1})$ & 0.260 \\
\hline $405 / 1226(33.0)$ & $66 / 146(45.2)$ & 0.003 \\
\hline 200/831 (24.1) & $26 / 86(30.2)$ & 0.207 \\
\hline 469/1079 (43.5) & $63 / 120(52.5)$ & 0.059 \\
\hline $61 / 872(7.0)$ & $25 / 108(23.1)$ & $<0.001$ \\
\hline $358 / 1523(23.5)$ & $88 / 172(51.2)$ & $<0.001$ \\
\hline $142 / 817(17.4)$ & $50 / 111(45.0)$ & $<0.001$ \\
\hline $6 / 303(2.0)$ & $9 / 32(28.1)$ & $<0.001$ \\
\hline
\end{tabular}

Case overlap among the data from different studies is avoided in the analyses in this table except for the potential overlap of a small number of cases of PTC from the TCGA database as explained in Tables 1, 2 and 3

${ }^{a}$ Comparisons were performed using independent $t$-test.

${ }^{b}$ Comparisons were performed using $\chi^{2}$ test. Information on certain parameters was not available in all studies and this table summarizes the data from studies that provided the available information as detailed in the Supplemental Table S1. 
ERC 150533-1/2/2016-16:12-SANKARS-551507-XML StyleD - pp. 143-155

\begin{tabular}{|c|c|c|c|c|c|}
\hline Author & Year & Type & & OR $(95 \% \mathrm{Cl})$ & Weight (\%) \\
\hline Liu X & 2014 & PTC & :- & $4.37(1.75,10.94)$ & 14.08 \\
\hline Melo M & 2014 & PTC & & $1.90(0.61,5.95)$ & 11.48 \\
\hline Xing M & 2014 & PTC & & $4.92(2.76,8.78)$ & 18.70 \\
\hline Muzza M & 2015 & PTC & & $0.88(0.36,2.15)$ & 14.39 \\
\hline Melo M & 2014 & FTC & & $4.32(0.78,23.88)$ & 6.97 \\
\hline Muzza M & 2015 & FTC & & $1.81(0.39,8.38)$ & 8.08 \\
\hline Melo M & 2014 & PDTC+ATC & & $1.64(0.30,8.86)$ & 7.10 \\
\hline Shi $X$ & 2015 & ATC & & $4.11(0.19,91.08)$ & 2.66 \\
\hline Qasem E & 2015 & Mixed & & $1.21(0.58,2.51)$ & 16.53 \\
\hline \multicolumn{3}{|c|}{ Overall $\left(I^{2}=53.1 \%, P=0.029\right)$} & 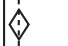 & $2.26(1.32,3.86)$ & 100.00 \\
\hline \multicolumn{3}{|c|}{ NOTE: Weights are from random effec } & & & \\
\hline
\end{tabular}

$\begin{array}{lll}0.1 & 1 & 10\end{array}$

Odds ratio

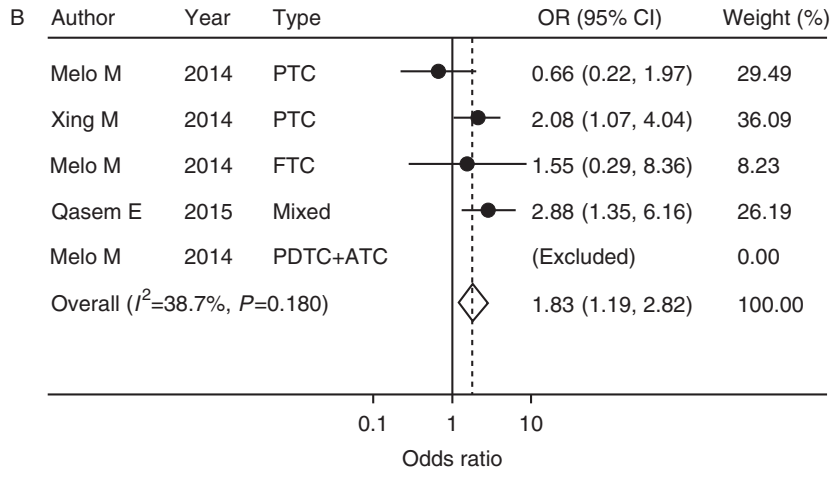

\section{Figure 1}

Meta-analysis of the association of TERT promoter mutations with extrathyroidal invasion (A) and vascular invasion (B) of thyroid cancer. The between-study heterogeneity was tested by a $\chi^{2}$-based $Q$-test and quantified by the $\mathrm{I}^{2}$ metric, which ranged from 0 to $100 \%$ and was considered low for $\mathrm{I}^{2}<25 \%$, modest for $25-50 \%$, and large for $>50 \%$ (Higgins et al. 2003). The combined OR was calculated by the fixed-effects model (the Mantel-Haenszel method) when between-study heterogeneity was absent (Mantel \& Haenszel 1959); otherwise the random-effects model (the Dersimonian and Laird method) was used (Dersimonian \& Laird 1986). The circles and horizontal lines correspond to the study-specific OR and $95 \% \mathrm{Cl}$ respectively. The combined ORs and their $95 \% \mathrm{Cls}$ are indicated by the diamonds. PTC, papillary thyroid cancer; FTC, follicular thyroid cancer; PDTC, poorly differentiated thyroid cancer; ATC, anaplastic thyroid cancer. OR, odds ratio.

male sex of patients is also associated with TERT promoter mutations, being $37.4 \%$ male in mutation-positive patients vs $24.8 \%$ in mutation-negative patients, $P<0.001$. Larger tumor size is associated with TERT promoter mutations, being $3.93 \pm 2.68$ vs $2.69 \pm 1.93 \mathrm{~cm}$ $(P<0.001)$ in TERT mutation-positive tumors vs TERT mutation-negative tumors. TERT promoter mutations are also significantly associated with extrathyroidal invasion, vascular invasion, distant metastasis and stage III/IV of thyroid cancer. Specifically, extrathyroidal invasion of thyroid cancer is seen in $55.6 \%$ of TERT mutation-positive patients vs $36.1 \%$ of TERT mutation-negative patients $(P<0.001)$. Meta-analysis reveals that TERT promoter mutations significantly increase the risk of extrathyroidal invasion with an odds ratio (OR) of 2.26 (95\% CI, $1.32-3.86 ; P=0.003$; Fig. $1 \mathrm{~A})$. Vascular invasion is also more common in the TERT promoter mutation-positive patients than the mutation-negative patients, being 42.2 vs $28.4 \%(P=0.002)$, with an OR of 1.83 (95\% CI, 1.19-2.82; $P=0.006$; Fig. $1 \mathrm{~B})$. There is no significant difference in lymph node metastasis between the TERT promoter mutation-positive and mutation-negative patients, although there is a strong trend of higher prevalence in the mutation-positive patients (Table 4). The distant metastasis is far more common in TERT promoter mutation-positive patients than mutationnegative patients, being 33.2 vs $10.5 \% \quad(P<0.001)$ (Table 4), with an OR of 4.87 (95\% CI, 2.31-10.26; $P<0.001$; Fig. 2A). Stage III/IV disease is similarly far more common in the TERT promoter mutation-positive patients than the mutation-negative patients, being 58.7 vs $25.7 \%(P<0.001)$ (Table 4$)$, with an OR of 4.08 (95\% CI, 3.00-5.54; $P<0.001$; Fig. 2B). Importantly, TERT promoter mutations are strongly associated with poor clinical outcomes of thyroid cancer on the analysis of large number of cases, including cancer recurrence and patient mortality (Table 4, Fig. 2C and D). Specifically, recurrence in TERT promoter mutation-positive patients vs mutationnegative patients is 52.1 vs $18.7 \%(P<0.001)$, with an OR of 4.89 (95\% CI, 3.36-7.13; $P<0.001$; Fig. 2C). Patient death rate is $41.9 \%$ in the TERT promoter mutationpositive patients vs $5.6 \%$ in the mutation-negative patients $(P<0.001$, Table 4$)$, with an OR of 10.26 (95\% CI, 4.11-25.60; $P<0.001$; Fig. 2D). It is worth noting that a significant and strong association of TERT promoter mutations with cancer recurrence (Fig. 2C) and patient death (Fig. 2D) was uniformly observed in all studies for PTC and FTC except for one study on ATC. Overall, the association of TERT promoter mutations with patient mortality is the strongest and most significant among all the clinicopathological parameters (Table 4 and Fig. 2). In fact, the four most aggressive clinicopathological parameters, including distant metastasis, disease stage III/IV, cancer recurrence and patient mortality, are all far more commonly and significantly associated with TERT promoter mutations than other clinicopathological parameters (Table 4 and Fig. 2). An analysis focused on PTC, the most common thyroid cancer, revealed similar results on the genetic-clinicopathological relationship as on the overall analysis of all cancers (Table 4). Analyses on other individual types of thyroid cancer showed mostly also a significant association between TERT promoter mutations and aggressive clinicopathological outcomes, particularly

Published by Bioscientifica Ltd 
ERC 150533-1/2/2016-16:12-SANKARS-551507-XML StyleD - pp. 143-155

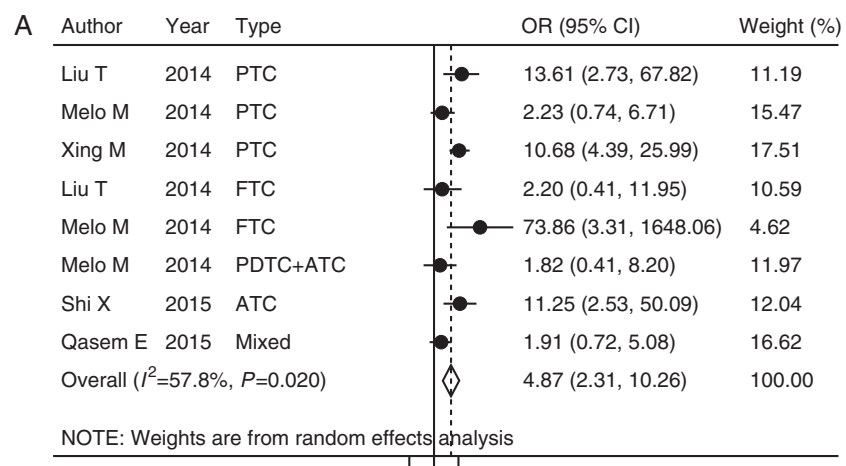
0.1110 Odds ratio

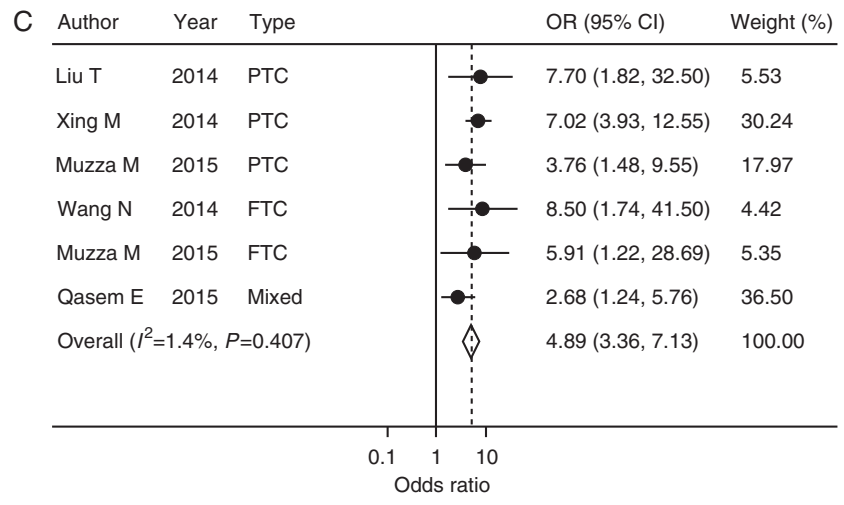

Figure 2

Meta-analysis of the association of TERT promoter mutations with thyroid cancer distant metastasis (A), tumor stage III/IV (B), tumor recurrence (C) and patients mortality (D). The between-study heterogeneity and combined OR were calculated as described in the legend to Fig. 1. The circles and horizontal

distant metastasis, disease stage III/IV, tumor recurrence and patient mortality, although in some cases just an association trend was seen, likely due to the small numbers of cases (Supplemental Table S1, see section on supplementary data given at the end of this article). Taken together, these data strongly suggest that TERT promoter mutations play an important role in the aggressiveness of thyroid cancer and are strong predictors for poor clinical outcomes of thyroid cancer. This conception is also consistent with our initial report that TERT promoter mutations were far more common in the aggressive thyroid cancers PDTC and ATC than the generally indolent differentiated PTC and FTC (Liu et al. 2013b), which have been confirmed in many subsequent reports (Tables 1 and 2). Interestingly, the TERT promoter mutation prevalence order of TCPTC $\gg$ CPTC $>$ FVPTC (Table 3 ) is similar to the clinicopathological aggressiveness order of the three PTC variants reported recently (Shi et al. 2016), further supporting a role of TERT promoter mutations in the development of aggressiveness of thyroid cancer.

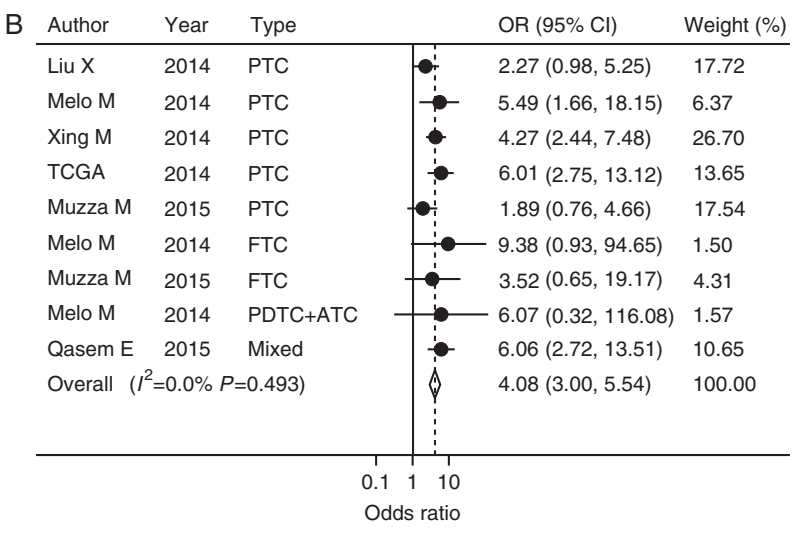

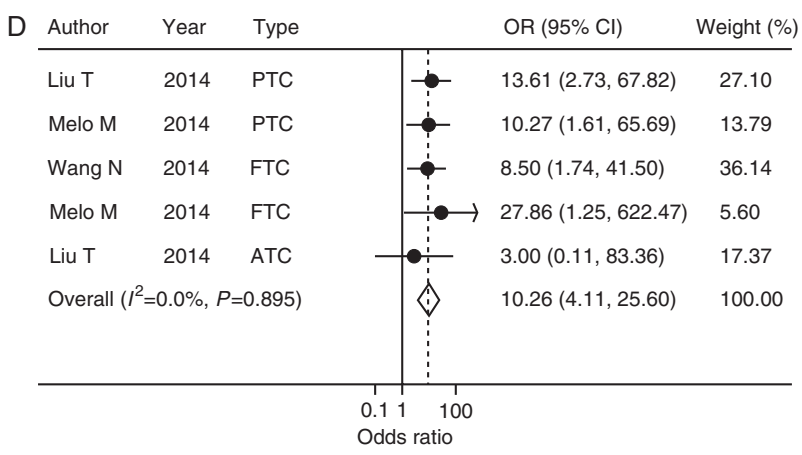

lines correspond to the study-specific OR and $95 \% \mathrm{CI}$. The combined ORs and their $95 \% \mathrm{Cls}$ are indicated by the diamonds. PTC, papillary thyroid cancer; FTC, follicular thyroid cancer; PDTC, poorly differentiated thyroid cancer; ATC, anaplastic thyroid cancer. OR, odds ratio.

\section{Association of TERT promoter mutations with BRAF V600E mutation in thyroid cancer}

$B R A F$ V600E is the most common oncogene in thyroid cancer that plays a fundamental role in the tumorigenesis and progression of thyroid cancer, particularly PTC (Xing 2005, 2007). Our initial study on TERT promoter mutations in thyroid cancer also reported an interesting association of TERT promoter mutations with the BRAF V600E mutation in PTC (Liu et al. 2013b). This finding was confirmed in many subsequent studies. As summarized in Table 5, on the overall analysis of the large pooled data, TERT promoter mutations are found in 146/1 294 (11.3\%) $B R A F$ V600E-negative cases vs 197/1 104 (17.8\%) BRAF V600E-positive cases; inversely, BRAF V600E is found in 907/2 055 (44.1\%) TERT mutation-negative cases vs 97/343 (57.4\%) TERT mutation-positive cases, with an OR of 2.46 (95\% CI, 1.89-3.20; $P<0.001$; Fig. 3). Similar results are obtained when analyses are performed only on PTC or advanced types of thyroid cancer, PDTC and ATC

Published by Bioscientifica Ltd. 
ERC 150533-1/2/2016-16:12-SANKARS-551507-XML StyleD - pp. 143-155

Table 5 Association of TERT promoter mutations with BRAF V600E mutation and in thyroid cancer

\begin{tabular}{|c|c|c|c|c|c|c|c|}
\hline \multirow[b]{2}{*}{ Cancer type } & \multirow[b]{2}{*}{ Study No. } & \multicolumn{2}{|c|}{ TERT mutation } & \multicolumn{2}{|c|}{ BRAF mutation } & \multirow[b]{2}{*}{$\boldsymbol{P}$} & \multirow[b]{2}{*}{ Reference } \\
\hline & & BRAF - & BRAF + & TERT - & TERT + & & \\
\hline \multirow[t]{11}{*}{ PTC } & 1 & $11 / 153(7.2)$ & 19/104 (18.3) & $85 / 227$ (37.4) & $19 / 30(63.3)$ & 0.009 & Liu et al. (2013b) \\
\hline & 2 & $6 / 12(50.0)$ & $2 / 17(11.8)$ & $15 / 21(71.4)$ & $2 / 8(25.0)$ & 0.038 & Landa et al. (2013) \\
\hline & 3 & $1 / 93(1.1)$ & $12 / 65(18.5)$ & $53 / 145(36.6)$ & $12 / 13(92.3)$ & $<0.001$ & Vinagre et al. (2013) \\
\hline & 4 & 6/158 (3.8) & $40 / 250(16.0)$ & $210 / 362(58.0)$ & $40 / 46(87.0)$ & $<0.001$ & Liu et al. (2014b) \\
\hline & 5 & 2/19 (10.5) & $11 / 32(34.4)$ & $21 / 38(55.3)$ & $11 / 13(84.6)$ & 0.096 & Liu et al. (2014a) \\
\hline & 6 & $6 / 153(3.9)$ & $18 / 148(12.2)$ & $130 / 277(46.9)$ & $18 / 24(75.0)$ & 0.008 & Melo et al. (2014) \\
\hline & 7 & 26/313 (8.3) & $35 / 194(18.0)$ & $159 / 446(35.7)$ & $35 / 61(57.4)$ & 0.001 & Xing et al. (2014a) \\
\hline & 8 & $10 / 161(6.2)$ & $26 / 223(11.7)$ & $197 / 348(56.6)$ & $26 / 36(72.2)$ & 0.071 & TCGA (2014) \\
\hline & 9 & $0 / 10(0)$ & $3 / 11(27.3)$ & $8 / 27(29.6)$ & $3 / 3(100)$ & 0.041 & Crescenzi et al. (2015) \\
\hline & 10 & $12 / 118(10.2)$ & 10/64 (15.6) & $54 / 160(33.8)$ & $10 / 22(45.5)$ & 0.281 & Muzza et al. (2015) \\
\hline & Subtotal & $68 / 953(7.1)$ & $145 / 939(15.4)$ & 794/1679 (47.3) & $145 / 213(68.1)$ & $<0.001$ & \\
\hline \multirow[t]{5}{*}{ PDTC \& ATC } & 2 & $21 / 49$ (42.9) & $19 / 29(65.5)$ & $10 / 38(26.3)$ & $19 / 40(47.5)$ & 0.053 & Landa et al. (2013) \\
\hline & 3 & $1 / 11(9.1)$ & $1 / 5(20.0)$ & $4 / 14(28.6)$ & $1 / 2(50.0)$ & 1.000 & Vinagre et al. (2013) \\
\hline & 6 & $17 / 55$ (30.9) & $4 / 10(40.0)$ & 6/44 (13.6) & $4 / 21(19.0)$ & 0.715 & Melo et al. (2014) \\
\hline & 11 & 28/90 (31.1) & $9 / 16(56.3)$ & $7 / 69$ (10.1) & 9/37 (24.3) & 0.052 & Shi et al. (2015) \\
\hline & Subtotal & 66/194 (34.0) & $32 / 55(58.2)$ & 23/151 (15.2) & $32 / 98$ (32.7) & 0.001 & \\
\hline Mixed & 12 & $12 / 147(8.2)$ & $20 / 110(18.2)$ & $90 / 225(40.0)$ & $20 / 32(62.5)$ & 0.016 & Qasem et al. (2015) \\
\hline Overall & & 146/1294 (11.3) & 197/1104 (17.8) & $907 / 2055$ (44.1) & $197 / 343(57.4)$ & $<0.001$ & \\
\hline
\end{tabular}

Because of the same investigator origin, there are potential overlaps of cases between Study Nos 1 and 7 and between Study Nos 3 and 6 . The data of Study Nos 1 and 3 were excluded from the pooled analyses. $P$ value was calculated by $\chi^{2}$ test or, for small cell sizes, Fisher's exact test. PTC, papillary thyroid cancer; PDTC, poorly differentiated thyroid cancer; ATC, anaplastic thyroid cancer.

(Table 5 and Fig. 3). Specifically, for PTC, TERT promoter mutations are found in 68/953 (7.1\%) BRAF V600Enegative cases vs 145/939 (15.4\%) BRAF V600E-positive cases; inversely, BRAF V600E is found in 794/1679 (47.3\%) TERT mutation-negative cases vs $145 / 213$ (68.1\%) TERT mutation-positive cases, with an OR of 2.37 (95\% CI, 1.38-4.05; $P<0.001$; Fig. 3). For PDTC/ATC, TERT promoter mutations are found in 66/194 (34.0\%) $B R A F$ V600E-negative cases vs 32/55 (58.2\%) BRAF V600Epositive cases; inversely, BRAF V600E is found in $23 / 151$ (15.2\%) TERT mutation-negative cases vs 32/98 (32.7\%) TERT mutation-positive cases, with an OR of 2.36 (95\% CI, $1.26-4.44 ; P=0.008$; Fig. 3). One exception to the highly positive association between TERT promoter mutations and BRAF V600E mutation reported in many studies and confirmed in this meta-analysis is the study by Landa et al. (2013) in which the authors reported an inverse relationship between TERT promoter mutations and the BRAF V600E mutation. It is not clear how to interpret this result, but this is the only study that has reported an inverse relationship between the two mutations. Interestingly, several studies also reported an association between TERT promoter mutations and the BRAF V600E mutation in melanoma (Horn et al. 2013, Griewank et al. 2014), suggesting that such a relationship between the two oncogenic genetic events may be a general phenomenon in human cancer.
We have demonstrated in a large study that coexistence of BRAF V600E and TERT promoter mutations constitutes a unique genetic background that drives particularly aggressive pathogenesis and poor clinical outcomes of PTC (Xing et al. 2014a). In this study, when the PTC patients were divided into four groups - no mutation, BRAF V600E mutation alone, TERT promoter mutation alone and coexistence of the two mutations, the group with both mutations was far more robustly associated with virtually all the conventional high-risk factors, such as large-tumor size, lymph-node metastasis, extrathyroidal invasion, vascular invasion, distant metastasis and advanced disease stages III/IV than other groups. $B R A F$ V600E and TERT promoter mutations each alone in fact had a modest effect and there was a strong incremental effect of the coexisting mutations over either mutation alone. This was even more clearly the case with the structural tumor recurrence patterns of PTC. Specifically, the recurrence of PTC was 8.7, 16.3, 19.2 and 68.6\% in the above defined corresponding four groups respectively over a median follow-up time of two years in 507 patients; these corresponded to hazard ratios (95\% CI) of 1.0, 2.24 (1.29-3.88), 1.69 (0.65-4.43) and 8.51 (4.84-14.97) respectively (Xing et al. 2014a). We also demonstrated a similar robust synergistic impact of coexisting $B R A F$ and TERT promoter mutations on disease-specific mortality of patients with PTC in 607 patients (Xing et al. 2014b).

Published by Bioscientifica Ltd. 


\begin{tabular}{|c|c|c|c|}
\hline Study ID & & OR $(95 \% \mathrm{Cl})$ & $\begin{array}{c}\text { Weight (\%) } \\
(\mathrm{M}-\mathrm{H})\end{array}$ \\
\hline \multicolumn{4}{|l|}{ PTC } \\
\hline Landa I (2013) & & $0.13(0.02,0.86)$ & 11.67 \\
\hline Liu X (2014) & $\div$ & $4.83(2.00,11.67)$ & 11.62 \\
\hline Liu T (2014) & $\rightarrow$ & $4.45(0.87,22.88)$ & 3.10 \\
\hline Melo M (2014) & $\rightarrow$ & $3.39(1.31,8.80)$ & 9.75 \\
\hline Xing M (2014) & é & $2.43(1.41,4.18)$ & 30.67 \\
\hline TCGA (2014) & 6 & $1.99(0.93,4.26)$ & 19.30 \\
\hline Crescenzi A (2015) & $i$ & $16.06(0.74,346.19)$ & 0.50 \\
\hline Muzza M (2015) & $2-$ & $1.64(0.66,4.03)$ & 13.39 \\
\hline M-H Subtotal $\left(I^{2}=53.8 \%, P=0.034\right)$ & 6 & $2.47(1.81,3.38)$ & 100.00 \\
\hline$D+L$ Subtotal & $\Leftrightarrow$ & $2.37(1.38,4.05)$ & \\
\hline \multicolumn{4}{|l|}{ PDTC \& ATC } \\
\hline Landa I (2013) & 4 & $2.53(0.98,6.56)$ & 44.06 \\
\hline Melo M (2014) & & $1.49(0.37,5.97)$ & 25.68 \\
\hline Shi X (2015) & & $2.85(0.96,8.42)$ & 30.26 \\
\hline M-H Subtotal $\left(I^{2}=0.0 \%, P=0.757\right)$ & $\Delta$ & $2.36(1.26,4.44)$ & 100.00 \\
\hline D+L Subtotal & $\Leftrightarrow$ & $2.36(1.25,4.46)$ & \\
\hline \multicolumn{4}{|l|}{ Mixed } \\
\hline Qasem E (2015) & $-\dot{-}$ & $2.50(1.16,5.37)$ & 100.00 \\
\hline M-H Subtotal $\left(I^{2}=. \%, P=.\right)$ & 6 & $2.50(1.16,5.37)$ & 100.00 \\
\hline$D+L$ Subtotal & 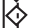 & $2.50(1.16,5.37)$ & \\
\hline M-H Overall $\quad\left(I^{2}=30.0 \%, P=0.152\right)$ & 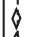 & $2.46(1.89,3.20)$ & \\
\hline D+L Overall & $\beta$ & $2.40(1.70,3.38)$ & \\
\hline
\end{tabular}

\section{Figure 3}

Meta-analysis of the association between BRAF V600E and TERT promoter mutations in thyroid cancer. The between-study heterogeneity and combined OR were calculated as described in Fig. 1. The circles and horizontal lines correspond to the study-specific OR and $95 \% \mathrm{CI}$. The combined ORs and their $95 \% \mathrm{Cls}$ are indicated by the diamonds. PTC, papillary thyroid cancer; PDTC, poorly differentiated thyroid cancer; ATC, anaplastic thyroid cancer. OR, odds ratio.

The effect of BRAF V600E mutation and TERT promoter mutation each alone on the mortality was also modest. In these analyses, the effect of coexisting BRAF V600E and TERT promoter mutations on PTC recurrence and patient mortality remained strongly significant even after the multivariate adjustment for multiple conventional risk factors and was incremental over either mutation alone. These results suggest that, indeed, $B R A F$ and TERT team up for trouble in thyroid cancer as commented in a recent commentary by Ngeow \& Eng (2014). These results also suggest that the role of $B R A F$ V600E mutation previously observed and the role of TERT promoter mutations discussed above in the aggressiveness of thyroid cancer are substantially attributable to the synergistic effect of the coexisting two mutations. One potential molecular mechanism to explain this synergistic effect of coexisting BRAF V600E and TERT promoter mutations is that, as discussed previously (Liu et al. 2013b, Xing et al. 2014a), the BRAF V600E-acctivated MAP kinase pathway upregulates the ETS transcriptional factors; the latter can then avidly bind to the consensus binding site in the TERT promoter created by C228T or C250T mutation to robustly upregulate the expression of TERT; highly expressed TERT would play a profound tumor-promoting role in thyroid cancer as in other human cancers as discussed above. As $B R A F \mathrm{~V} 600 \mathrm{E}$ has been shown to play an important role in the oncogenic extracellular micro environmental changes in the pathogenesis of thyroid cancer (Nucera et al. 2010, 2011, Nucera 2013), it remains an interesting possibility to be explored that the synergistic effects of $B R A F$ V600E and TERT promoter mutations on the progression and aggressiveness of thyroid cancer may involve tumor invasion-promoting molecular changes in the micro environments of thyroid cancer.

\section{Association of TERT promoter mutations with RAS mutations in thyroid cancer}

RAS mutations are major oncogenic genetic alterations and commonly occur in thyroid cancer, particularly in FTC, PDTC and ATC (Xing 2013). Several studies investigated the relationship between RAS mutations and TERT promoter mutations in thyroid cancers (Table 6). One individual study on FTC showed a significant association

Table 6 Association of TERT promoter mutations with RAS mutations in thyroid cancer

\begin{tabular}{|c|c|c|c|c|c|c|c|c|}
\hline \multirow[b]{2}{*}{ Cancer type } & \multirow[b]{2}{*}{ Study No. } & \multicolumn{2}{|c|}{ TERT mutation } & \multicolumn{2}{|c|}{ RAS mutation } & \multirow[b]{2}{*}{$\boldsymbol{P}$} & \multirow[b]{2}{*}{ OR $(95 \% \mathrm{CI})$} & \multirow[b]{2}{*}{ Reference } \\
\hline & & RAS - & RAS + & TERT - & TERT + & & & \\
\hline \multirow[t]{4}{*}{ FTC } & 1 & $4 / 50(8.0)$ & $5 / 14(35.7)$ & 9/55 (16.4) & $5 / 9(55.6)$ & 0.019 & $6.39(1.43-28.53)$ & Vinagre et al. (2013) \\
\hline & 2 & $7 / 50(14.0)$ & $4 / 14(28.6)$ & $10 / 53(18.9)$ & $4 / 11(36.4)$ & 0.237 & $2.46(0.60-10.05)$ & Melo et al. (2014) \\
\hline & 3 & $6 / 44(13.6)$ & $2 / 14$ (14.3) & $12 / 50(24.0)$ & $2 / 8(25.0)$ & 1.000 & $1.06(0.19-5.94)$ & Muzza et al. (2015) \\
\hline & Subtotal & $13 / 94(13.8)$ & $6 / 28(21.4)$ & $22 / 103$ (21.4) & $6 / 19(31.6)$ & 0.330 & $1.71(0.58-5.02) *$ & \\
\hline \multirow[t]{4}{*}{ PDTC \& ATC } & 1 & $4 / 29(13.8)$ & $1 / 1(100)$ & $0 / 25(0)$ & $1 / 5(20.0)$ & 0.167 & $17.00(0.59-486.41)$ & Vinagre et al. (2013) \\
\hline & 2 & $13 / 44(29.5)$ & $8 / 17(47.1)$ & $9 / 40(22.5)$ & $8 / 21(38.1)$ & 0.197 & $2.12(0.67-6.71)$ & Melo et al. (2014) \\
\hline & 4 & $26 / 58(44.8)$ & $14 / 20(70.0)$ & $6 / 38(15.8)$ & $14 / 40(35.0)$ & 0.052 & $2.87(0.97-8.52)$ & Landa et al. (2013) \\
\hline & Subtotal & $39 / 102(38.2)$ & $22 / 37(59.5)$ & $15 / 78(19.2)$ & $22 / 61(36.1)$ & 0.026 & $2.50(1.14-5.50)^{\dagger}$ & \\
\hline Overall & & $52 / 196(26.5)$ & $28 / 65(43.1)$ & $37 / 181(20.4)$ & $28 / 80(35.0)$ & 0.012 & $2.21(1.18-4.15)^{\ddagger}$ & \\
\hline
\end{tabular}

Because of the same investigator origin, there are potential overlaps of cases between Study Nos 1 and 2 . The data of Study No. 1 was excluded from the pooled analyses. The combined odds ratio (OR) and $95 \% \mathrm{Cl}$ were calculated by meta-analysis. $P$ value was calculated by $\chi^{2}$ test or, for small cell sizes, Fisher's exact test. ${ }^{*} P=0.327 ;{ }^{\dagger} P=0.022 ;{ }^{\ddagger} P=0.014$. FTC, follicular thyroid cancer; PDTC, poorly differentiated thyroid cancer; ATC, anaplastic thyroid cancer.

http://erc.endocrinology-journals.org DOI: 10.1530/ERC-15-0533
(C) 2016 Society for Endocrinology Printed in Great Britain
Published by Bioscientifica Ltd 
between TERT promoter mutations and RAS mutations (Vinagre et al. 2013). The remaining studies individually showed a trend of such association. The pooled data of PDTC and ATC show a significant association between TERT promoter mutations and RAS mutations, with an OR of 2.50 (95\% CI, 1.14-5.50, $P=0.022)$. When all the thyroid cancers are pooled together, this association remains significant, with an OR of 2.21 (95\% CI, 1.18-4.15) and an even more significant $P$ value of 0.014 (Table 6). The biological and clinical significance of this association remains to be investigated. It is possible that, like the coexisting TERT promoter mutations and BRAF mutations in PTC, coexisting TERT promoter and RAS mutations may also play a cooperative role in thyroid tumorigenesis and promote tumor aggressiveness and poor clinical outcomes of thyroid cancer. BRAF V600E synergizes the role of TERT promoter mutations through activating the MAP kinase pathway. RAS mutations likely synergize the role of TERT promoter mutations through activating the PI3K pathway since RAS mutations preferentially activate this pathway over the MAP kinase pathway in thyroid cancer (Xing 2013). As such, coexistence of TERT promoter mutations and RAS mutations may represent a unique genetic background that is particularly important in FTC, PDTC and ATC in which RAS mutations are particularly common and the PI3K pathway plays a particularly important role (Saji \& Ringel 2010, Xing 2010, 2013). These remain to be further investigated and established in the future.

\section{Conclusion}

It has been $<3$ years since the initial report on TERT promoter mutations in thyroid cancer (Liu et al. 2013b), while substantial progress has occurred in this exciting new field. Much has been known about the biological and clinical relevance of these mutations in thyroid cancer in this short time. Studies from various populations and regions in the world uniformly found TERT promoter mutations to be present in thyroid cancers, but not benign thyroid tumors, and be more common in aggressive types of thyroid cancers. These mutations are also more commonly associated with aggressive tumor behaviors and poor clinical outcomes, including tumor recurrence and patient mortality. A particular interesting and important aspect of TERT promoter mutations in PTC is their association with the BRAF V600E mutation and the robust synergistic impact of the coexisting two mutations on aggressive clinicopathological outcomes of PTC, particularly tumor recurrence and patient mortality.
These results are consistent with the proposed model in which TERT promoter mutations create consensus binding sites for ETS transcriptional factors for the latter to activate the expression of TERT, a process that can be upregulated by the BRAF V600E/MAP kinase signaling pathway. A similar synergistic effect between TERT promoter mutations and RAS mutations, likely through activating the PI3K pathway, may also exist in thyroid cancer. These clinicopathological data strongly support a prominent role of TERT promoter mutations in the tumorigenesis and progression of thyroid cancer, which is well corroborated by previous results on similar differential expression patterns of TERT in benign and malignant thyroid tumors. As such, TERT promoter mutations are promising diagnostic and prognostic genetic markers for thyroid cancer, which is highly applicable clinically as demonstrated recently by applying them to thyroid fine needle aspiration biopsy for such purposes (Liu \& Xing 2014, Nikiforov et al. 2014, Shrestha et al. 2015). Future studies will need to more specifically define such clinical utilities, elucidate the biological mechanisms of the role of TERT promoter mutations in thyroid tumorigenesis, and explore and establish the therapeutic utilities of targeting TERT for thyroid cancer.

\section{Supplementary data}

This is linked to the online version of the paper at http://dx.doi.org/10.1530/ ERC-15-0533.

\section{Declaration of interest}

The authors declare that there is no conflict of interest that could be perceived as prejudicing the impartiality of the review.

\section{Funding}

This work was supported by NIH grants R01CA189224 and R01CA113507 to M Xing.

\section{References}

Asaad NY, Abd El-Wahed MM \& Mohammed AG 2006 Human telomerase reverse transcriptase (hTERT) gene expression in thyroid carcinoma: diagnostic and prognostic role. Journal of the Egyptian National Cancer Institute 18 8-16.

Ballester LY, Sarabia SF, Sayeed H, Patel N, Baalwa J, Athanassaki I, Hernandez JA, Fang E, Quintanilla NM, Roy A et al. 2015 Integrating molecular testing in the diagnosis and management of children with thyroid lesions. Pediatric and Developmental Pathology [in press]. (doi:10.2350/15-05-1638-OA.1)

Bell RJ, Rube HT, Kreig A, Mancini A, Fouse SD, Nagarajan RP, Choi S, Hong C, He D, Pekmezci M et al. 2015 Cancer. The transcription factor

Published by Bioscientifica Ltd. 
GABP selectively binds and activates the mutant TERT promoter in cancer. Science 348 1036-1039. (doi:10.1126/science.aab0015)

de Biase D, Gandolfi G, Ragazzi M, Eszlinger M, Sancisi V, Gugnoni M, Visani M, Pession A, Casadei G, Durante C et al. 2015 TERT promoter mutations in papillary thyroid microcarcinomas. Thyroid $\mathbf{2 5}$ 1013-1019. (doi:10.1089/thy.2015.0101)

Blasco MA 2005 Telomeres and human disease: ageing, cancer and beyond. Nature Review Genetics 6 611-622. (doi:10.1038/nrg1656)

Bodnar AG, Ouellette M, Frolkis M, Holt SE, Chiu CP, Morin GB, Harley CB, Shay JW, Lichtsteiner S \& Wright WE 1998 Extension of life-span by introduction of telomerase into normal human cells. Science $\mathbf{2 7 9}$ 349-352. (doi:10.1126/science.279.5349.349)

Bojesen SE, Pooley KA, Johnatty SE, Beesley J, Michailidou K, Tyrer JP, Edwards SL, Pickett HA, Shen HC, Smart CE et al. 2013 Multiple independent variants at the TERT locus are associated with telomere length and risks of breast and ovarian cancer. Nature Genetics $\mathbf{4 5}$ 371-384. (doi:10.1038/ng.2566)

Cancer Genome Atlas Research Network 2014 Integrated genomic characterization of papillary thyroid carcinoma. Cell 159 676-690. (doi:10.1016/j.cell.2014.09.050)

Chindris AM, Casler JD, Bernet VJ, Rivera M, Thomas C, Kachergus JM, Necela BM, Hay ID, Westphal SA, Grant CS et al. 2015 Clinical and molecular features of Hurthle cell carcinoma of the thyroid. Journal of Clinical Endocrinology and Metabolism 100 55-62. (doi:10.1210/jc.2014-1634)

Choi J, Southworth LK, Sarin KY, Venteicher AS, Ma W, Chang W, Cheung P, Jun S, Artandi MK, Shah N et al. 2008 TERT promotes epithelial proliferation through transcriptional control of a Myc- and Wnt-related developmental program. PLoS Genetics 4 e10. (doi:10.1371/journal.pgen.0040010)

Codd V, Nelson CP, Albrecht E, Mangino M, Deelen J, Buxton JL, Hottenga JJ, Fischer K, Esko T, Surakka I et al. 2013 Identification of seven loci affecting mean telomere length and their association with disease. Nature Genetics 45 422-427. (doi:10.1038/ng.2528)

Crescenzi A, Trimboli P, Modica DC, Taffon C, Guidobaldi L, Taccogna S, Rainer A, Trombetta M, Papini E \& Zelano G 2015 Preoperative assessment of TERT promoter mutation on thyroid core needle biopsies supports diagnosis of malignancy and addresses surgical strategy. Hormone and Metabolic Research [in press]. (doi:10.1055/s-00351548873)

DerSimonian R \& Laird N 1986 Meta-analysis in clinical trials. Controlled Clinical Trials 7 177-188. (doi:10.1016/0197-2456(86)90046-2)

Dettmer MS, Schmitt A, Steinert H, Capper D, Moch H, Komminoth P \& Perren A 2015 Tall cell papillary thyroid carcinoma: new diagnostic criteria and mutations in BRAF and TERT. Endocrine-Related Cancer 22 419-429. (doi:10.1530/ERC-15-0057)

Feng J, Funk WD, Wang SS, Weinrich SL, Avilion AA, Chiu CP, Adams RR, Chang E, Allsopp RC, Yu J et al. 1995 The RNA component of human telomerase. Science 269 1236-1241. (doi:10.1126/science.7544491)

Gandolfi G, Ragazzi M, Frasoldati A, Piana S, Ciarrocchi A \& Sancisi V 2015 TERT promoter mutations are associated with distant metastases in papillary thyroid carcinoma. European Journal of Endocrinology 172 403-413. (doi:10.1530/EJE-14-0837)

Ghosh A, Saginc G, Leow SC, Khattar E, Shin EM, Yan TD, Wong M, Zhang Z, Li G, Sung WK et al. 2012 Telomerase directly regulates NFkB-dependent transcription. Nature Cell Biology 14 1270-1281. (doi:10.1038/ncb2621)

Gonzalez-Suarez E, Samper E, Ramirez A, Flores JM, Martin-Caballero J, Jorcano JL \& Blasco MA 2001 Increased epidermal tumors and increased skin wound healing in transgenic mice overexpressing the catalytic subunit of telomerase, mTERT, in basal keratinocytes. EMBO Journal 20 2619-2630. (doi:10.1093/emboj/20.11.2619)

Greider CW \& Blackburn EH 2004 Tracking telomerase. Cell 116 S83-S86. (doi:10.1016/S0092-8674(04)00053-4)

Griewank KG, Murali R, Puig-Butille JA, Schilling B, Livingstone E, Potrony M, Carrera C, Schimming T, Möller I, Schwamborn M et al.
2014 TERT promoter mutation status as an independent prognostic factor in cutaneous melanoma. Journal of National Cancer Institute $\mathbf{1 0 6}$ pii: dju246. (doi:10.1093/jnci/dju246)

Hahn WC, Counter CM, Lundberg AS, Beijersbergen RL, Brooks MW \& Weinberg RA 1999 Creation of human tumour cells with defined genetic elements. Nature 400 464-468. (doi:10.1038/22780)

Hanahan D \& Weinberg RA 2011 Hallmarks of cancer: the next generation. Cell 144 646-674. (doi:10.1016/j.cell.2011.02.013)

Harley CB \& Villeponteau B 1995 Telomeres and telomerase in aging and cancer. Current Opinion in Genetics \& Development 5 249-255. (doi:10.1016/0959-437X(95)80016-6)

Higgins JP, Thompson SG, Deeks JJ \& Altman DG 2003 Measuring inconsistency in meta-analyses. British Medical Journal 327 557-560. (doi:10.1136/bmj.327.7414.557)

Horn S, Figl A, Rachakonda PS, Fischer C, Sucker A, Gast A, Kadel S, Moll I, Nagore E, Hemminki K et al. 2013 TERT promoter mutations in familial and sporadic melanoma. Science 339 959-961. (doi:10.1126/science. 1230062)

Howlader N, Noone AM, Krapcho M, Garshell J, Miller D, Altekruse SF, Kosary CL, Yu M, Ruhl J, Tatalovich Z, et al. 2015 SEER Cancer Statistics Review, 1975-2012, Bethesda, MD: National Cancer Institute, http:// seer.cancer.gov/csr/1975-2012/, based on November 2014 SEER data submission, posted to the SEER web site, April 2015. Accessed on October 25, 2015.

Hrdlickova R, Nehyba J \& Bose HR Jr 2012 Alternatively spliced telomerase reverse transcriptase variants lacking telomerase activity stimulate cell proliferation. Molecular Cell Biology 32 4283-4296. (doi:10.1128/MCB. 00550-12)

Huang FW, Hodis E, Xu MJ, Kryukov GV, Chin L \& Garraway LA 2013 Highly recurrent TERT promoter mutations in human melanoma. Science 339 957-959. (doi:10.1126/science.1229259)

Hundahl SA, Fleming ID, Fremgen AM \& Menck HR 1998 A National Cancer Data Base report on 53,856 cases of thyroid carcinoma treated in the US, 1985-1995 [see comments]. Cancer 83 2638-2648. (doi:10. 1002/(SICI)1097-0142(19981215)83:12<2638::AID-CNCR31>3.0. $\mathrm{CO} ; 2-1)$

Ito Y, Yoshida H, Tomoda C, Uruno T, Takamura Y, Miya A, Kobayashi K, Matsuzuka F, Kuma K \& Miyauchi A 2005 Telomerase activity in thyroid neoplasms evaluated by the expression of human telomerase reverse transcriptase (hTERT). Anticancer Research 25 509-514.

Janknecht R 2004 On the road to immortality: hTERT upregulation in cancer cells. FEBS Letters 564 9-13. (doi:10.1016/S0014-5793 (04)00356-4)

Killela PJ, Reitman ZJ, Jiao Y, Bettegowda C, Agrawal N, Diaz LA Jr, Friedman AH, Friedman H, Gallia GL, Giovanella BC et al. 2013 TERT promoter mutations occur frequently in gliomas and a subset of tumors derived from cells with low rates of self-renewal. PNAS 110 6021-6026. (doi:10.1073/pnas.1303607110)

Kim NW, Piatyszek MA, Prowse KR, Harley CB, West MD, Ho PL, Coviello GM, Wright WE, Weinrich SL \& Shay JW 1994 Specific association of human telomerase activity with immortal cells and cancer. Science 266 2011-2015. (doi:10.1126/science.7605428)

Koh CM, Khattar E, Leow SC, Liu CY, Muller J, Ang WX, Li Y, Franzoso G, Li S, Guccione E et al. 2015 Telomerase regulates MYC-driven oncogenesis independent of its reverse transcriptase activity. Journal of Clinical Investigation 125 2109-2122. (doi:10.1172/JCI79134)

Landa I, Ganly I, Chan TA, Mitsutake N, Matsuse M, Ibrahimpasic T, Ghossein RA \& Fagin JA 2013 Frequent somatic TERT promoter mutations in thyroid cancer: higher prevalence in advanced forms of the disease. Journal of Clinical Endocrinology and Metabolism 98 E1562-E1566. (doi:10.1210/jc.2013-2383)

Lee YS, Kim Y, Jeon S, Bae JS, Jung SL \& Jung CK 2015 Cytologic, clinicopathologic, and molecular features of papillary thyroid carcinoma with prominent hobnail features: 10 case reports and systematic literature review. International Journal of Clinical and Experimental Pathology 8 7988-7997. 
Liu R \& Xing M 2014 Diagnostic and prognostic TERT promoter mutations in thyroid fine-needle aspiration biopsy. Endocrine-Related Cancer 21 825-830. (doi:10.1530/ERC-14-0359)

Liu X, Wu G, Shan Y, Hartmann C, von Deimling A \& Xing M 2013a Highly prevalent TERT promoter mutations in bladder cancer and glioblastoma. Cell Cycle 12 1637-1638. (doi:10.4161/cc.24662)

Liu X, Bishop J, Shan Y, Pai S, Liu D, Murugan AK, Sun H, El-Naggar AK \& Xing M 2013b Highly prevalent TERT promoter mutations in aggressive thyroid cancers. Endocrine-Related Cancer 20 603-610. (doi:10.1530/ ERC-13-0210)

Liu T, Wang N, Cao J, Sofiadis A, Dinets A, Zedenius J, Larsson C \& Xu D $2014 a$ The age- and shorter telomere-dependent TERT promoter mutation in follicular thyroid cell-derived carcinomas. Oncogene $\mathbf{3 3}$ 4978-4984. (doi:10.1038/onc.2013.446)

Liu X, Qu S, Liu R, Sheng C, Shi X, Zhu G, Murugan AK, Guan H, $\mathrm{Yu} \mathrm{H}$, Wang Y et al. $2014 b$ TERT promoter mutations and their association with BRAF V600E mutation and aggressive clinicopathological characteristics of thyroid cancer. Journal of Clinical Endocrinology and Metabolism 99 E1130-E1136. (doi:10.1210/jc. 2013-4048)

Low KC \& Tergaonkar V 2013 Telomerase: central regulator of all of the hallmarks of cancer. Trends in Biochemical Sciences 38 426-434. (doi:10.1016/j.tibs.2013.07.001)

Mantel N \& Haenszel W 1959 Statistical aspects of the analysis of data from retrospective studies of disease. Journal of National Cancer Institute 22 719-748.

Melo M, da Rocha AG, Vinagre J, Batista R, Peixoto J, Tavares C, Celestino R, Almeida A, Salgado C, Eloy C et al. 2014 TERT promoter mutations are a major indicator of poor outcome in differentiated thyroid carcinomas. Journal of Clinical Endocrinology and Metabolism 99 E754-E765. (doi:10.1210/jc.2013-3734)

Meyerson M, Counter CM, Eaton EN, Ellisen LW, Steiner P, Caddle SD, Ziaugra L, Beijersbergen RL, Davidoff MJ, Liu Q et al. 1997 hEST2, the putative human telomerase catalytic subunit gene, is up-regulated in tumor cells and during immortalization. Cell 90 785-795. (doi:10.1016/S0092-8674(00)80538-3)

Moyzis RK, Buckingham JM, Cram LS, Dani M, Deaven LL, Jones MD, Meyne J, Ratliff RL \& Wu JR 1988 A highly conserved repetitive DNA sequence, (TTAGGG)n, present at the telomeres of human chromosomes. PNAS 85 6622-6626. (doi:10.1073/pnas.85. 18.6622)

Muzza M, Colombo C, Rossi S, Tosi D, Cirello V, Perrino M, De Leo S, Magnani E, Pignatti E, Vigo B et al. 2015 Telomerase in differentiated thyroid cancer: promoter mutations, expression and localization. Molecular and Cellular Endocrinology 399 288-295. (doi:10.1016/j.mce. 2014.10.019)

Ngeow J \& Eng C 2014 TERT and BRAF in thyroid cancer: teaming up for trouble. Journal of Clinical Oncology 32 2683-2684. (doi:10.1200/JCO. 2014.56.5614)

Nikiforov YE, Carty SE, Chiosea SI, Coyne C, Duvvuri U, Ferris RL, Gooding WE, Hodak SP, LeBeau SO, Ohori NP et al. 2014 Highly accurate diagnosis of cancer in thyroid nodules with follicular neoplasm/suspicious for a follicular neoplasm cytology by ThyroSeq v2 next-generation sequencing assay. Cancer 120 3627-3634. (doi:10.1002/cncr.29038)

Nucera C 2013 Targeting thyroid cancer microenvironment: basic research and clinical applications. Frontiers in Endocrinology 4 167. (doi:10.3389/ fendo.2013.00167)

Nucera C, Porrello A, Antonello ZA, Mekel M, Nehs MA, Giordano TJ, Gerald D, Benjamin LE, Priolo C, Puxeddu E et al. 2010 B-Raf(V600E) and thrombospondin-1 promote thyroid cancer progression. PNAS $\mathbf{1 0 7}$ 10649-10654. (doi:10.1073/pnas.1004934107)

Nucera C, Lawler J \& Parangi S 2011 BRAF(V600E) and microenvironment in thyroid cancer: a functional link to drive cancer progression. Cancer Research 71 2417-2422. (doi:10.1158/0008-5472.CAN-10-3844)
Qasem E, Murugan AK, Al-Hindi H, Xing M, Almohanna M, Alswailem M \& Alzahrani AS 2015 TERT promoter mutations in thyroid cancer: a report from a Middle Eastern population. Endocrine-Related Cancer 22 901-908. (doi:10.1530/ERC-15-0396)

Rafnar T, Sulem P, Stacey SN, Geller F, Gudmundsson J, Sigurdsson A, Jakobsdottir M, Helgadottir H, Thorlacius S, Aben KK et al. 2009 Sequence variants at the TERT-CLPTM1L locus associate with many cancer types. Nature Genetics 41 221-227. (doi:10.1038/ng.296)

Saji M \& Ringel MD 2010 The PI3K-Akt-mTOR pathway in initiation and progression of thyroid tumors. Molecular and Cellular Endocrinology 321 20-28. (doi:10.1016/j.mce.2009.10.016)

Saji M, Xydas S, Westra WH, Liang CK, Clark DP, Udelsman R, Umbricht CB, Sukumar S \& Zeiger MA 1999 Human telomerase reverse transcriptase (hTERT) gene expression in thyroid neoplasms. Clinical Cancer Research $\mathbf{5}$ 1483-1489.

Sarin KY, Cheung P, Gilison D, Lee E, Tennen RI, Wang E, Artandi MK, Oro AE \& Artandi SE 2005 Conditional telomerase induction causes proliferation of hair follicle stem cells. Nature 436 1048-1052. (doi:10.1038/nature03836)

Shay JW \& Bacchetti S 1997 A survey of telomerase activity in human cancer. European Journal of Cancer 33 787-791. (doi:10.1016/ S0959-8049(97)00062-2)

Shi X, Liu R, Qu S, Zhu G, Bishop J, Liu X, Sun H, Shan Z, Wang E, Luo Y et al. 2015 Association of TERT promoter mutation 1,295,228 C $>$ T with BRAF V600E mutation, older patient age, and distant metastasis in anaplastic thyroid cancer. Journal of Clinical Endocrinology and Metabolism 100 E632-E637. (doi:10.1210/jc.2014-3606)

Shi X, Liu R, Basolo F, Giannini R, Shen X, Teng D, Guan H, Shan Z, Teng W, Musholt TJ et al. 2016 Differential clinicopathological risk and prognosis of major papillary thyroid cancer variants. Journal of Clinical Endocrinology and Metabolism 101 264-274. (doi:10.1210/jc. 2015-2917)

Shrestha RT, Karunamurthy A, Amin K, Nikiforov YE \& Caramori ML 2015 Multiple mutations detected preoperatively may predict aggressive behavior of papillary thyroid cancer and guide management - a case report. Thyroid 25 1375-1378. (doi:10.1089/thy.2015.0278)

Siegel R, Ma J, Zou Z \& Jemal A 2014 Cancer statistics, 2014. CA: A Cancer Journal for Clinicians 64 9-29. (doi:10.3322/caac.21208)

Smith LL, Coller HA \& Roberts JM 2003 Telomerase modulates expression of growth-controlling genes and enhances cell proliferation. Nature Cell Biology 5 474-479. (doi:10.1038/ncb985)

Stewart SA, Hahn WC, O'Connor BF, Banner EN, Lundberg AS, Modha P, Mizuno H, Brooks MW, Fleming M, Zimonjic DB et al. 2002 Telomerase contributes to tumorigenesis by a telomere length-independent mechanism. PNAS 99 12606-12611. (doi:10.1073/ pnas.182407599)

Teng L, Specht MC, Barden CB \& Fahey TJ III 2003 Antisense hTERT inhibits thyroid cancer cell growth. Journal of Clinical Endocrinology and Metabolism 88 1362-1366. (doi:10.1210/jc.2002-021222)

Umbricht CB, Saji M, Westra WH, Udelsman R, Zeiger MA \& Sukumar S 1997 Telomerase activity: a marker to distinguish follicular thyroid adenoma from carcinoma. Cancer Research 57 2144-2147.

Vinagre J, Almeida A, Populo H, Batista R, Lyra J, Pinto V, Coelho R, Celestino R, Prazeres H, Lima L et al. 2013 Frequency of TERT promoter mutations in human cancers. Nature Communications 42185. (doi:10.1038/ncomms3185)

Wang Z, Zhu B, Zhang M, Parikh H, Jia J, Chung CC, Sampson JN, Hoskins JW, Hutchinson A, Burdette L et al. 2014a Imputation and subset-based association analysis across different cancer types identifies multiple independent risk loci in the TERT-CLPTM1L region on chromosome 5p15.33. Human Molecular Genetics 23 6616-6633. (doi:10.1093/hmg/ddu363)

Wang N, Liu T, Sofiadis A, Juhlin CC, Zedenius J, Hoog A, Larsson C \& Xu D $2014 b$ TERT promoter mutation as an early genetic event activating telomerase in follicular thyroid adenoma (FTA) and atypical FTA. Cancer 120 2965-2979. (doi:10.1002/cncr.28800) 
ERC 150533-1/2/2016-16:12-SANKARS-551507-XML StyleD - pp. 143-155

Review

$R$ Liu and $M$ Xing

TERT and thyroid cancer

Wang N, Xu D, Sofiadis A, Hoog A, Vukojevic V, Backdahl M, Zedenius J \& Larsson C 2014c Telomerase-dependent and independent telomere maintenance and its clinical implications in medullary thyroid carcinoma. Journal of Clinical Endocrinology and Metabolism 99 E1571-E1579. (doi:10.1210/jc.2014-1158)

Wyatt HD, West SC \& Beattie TL 2010 InTERTpreting telomerase structure and function. Nucleic Acids Research 38 5609-5622. (doi:10.1093/nar/ gkq370)

Xing M 2005 BRAF mutation in thyroid cancer. Endocrine-Related Cancer 12 245-262. (doi:10.1677/erc.1.0978)

Xing M 2007 BRAF mutation in papillary thyroid cancer: pathogenic role, molecular bases, and clinical implications. Endocrine Reviews $\mathbf{2 8}$ 742-762. (doi:10.1210/er.2007-0007)
Xing M 2010 Genetic alterations in the phosphatidylinositol-3 kinase/Akt pathway in thyroid cancer. Thyroid 20 697-706. (doi:10.1089/ thy.2010.1646)

Xing M 2013 Molecular pathogenesis and mechanisms of thyroid cancer. Nature Review Cancer 13 184-199. (doi:10.1038/nrc3431)

Xing M, Liu R, Liu X, Murugan AK, Zhu G, Zeiger MA, Pai S \& Bishop J $2014 a$ BRAF V600E and TERT promoter mutations cooperatively identify the most aggressive papillary thyroid cancer with highest recurrence. Journal of Clinical Oncology 32 2718-2726. (doi:10.1200/ JCO.2014.55.5094)

Xing M, Liu R \& Bishop J $2014 b$ TERT promoter and BRAF mutations cooperatively promote papillary thyroid cancer-related mortality. Thyroid 24 (S1) A-131. (doi:10.1089/thy.2014.2410.abstracts.sc)

Received in final form 17 December 2015

Accepted 24 December 2015

Made available online as an Accepted Preprint

5 January 2016
Published by Bioscientifica Ltd. 